\title{
Neighbourhood deprivation and outlet density for tobacco, alcohol and fast food: first hints of obesogenic and addictive environments in Germany
}

\author{
Sven Schneider ${ }^{1, *}$ and Johannes Gruber ${ }^{2,3}$ \\ 'Mannheim Institute of Public Health, Social and Preventive Medicine, Mannheim Medical Faculty, Heidelberg \\ University, Ludolf-Krehl-Strasse 7-1 1, D-68167 Mannheim, Germany: ${ }^{2}$ Institute of Transport Research, German \\ Aerospace Center (DLR), Berlin, Germany: ${ }^{3}$ Department of Geography, University of Munich, Munich, Germany
}

Submitted 7 September 2011: Final revision received 1 June 2012: Accepted 8 June 2012: First published online 10 July 2012

\begin{abstract}
Objective: The current discussion regarding 'place effects on health' is increasingly focusing on the characteristics of a specific physical environment. Our study investigated whether socially deprived residential areas are more likely than affluent neighbourhoods to provide access to addictive substances and fast food. Design: In this ecological study the total number of tobacco, alcohol and fastfood outlets was recorded and visualized using a geographic information system. Area affluence was measured through the percentage of parents with children of kindergarten or school age with joint annual taxable income $<€ 12272$.

Setting: Eighteen social areas in Cologne, Germany.

Subjects: All social areas in four districts in Cologne, Germany, with a total of 92000 inhabitants, were analysed.

Results: In the investigation area, 339 tobacco, 353 alcohol and sixty-seven fastfood outlets were identified. As area affluence declined the availability of the following potentially health damaging sources increased: cigarettes (Kendall's tau $=0.433 ; P=0 \cdot 012$ ), alcohol (Kendall's tau $=0 \cdot 341, P=0 \cdot 049$ ) and fast food (Kendall's tau $=0 \cdot 473 ; P=0 \cdot 009$ ).

Conclusions: The availability of addictive substances and fast food can be seen to have a contextual influence on an individual's lifestyle and can, in the form of physical exposure to obesogenic and addictive environments, contribute to a culmination of health risks.
\end{abstract}

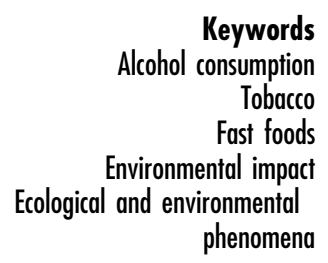

Until well into the 1980s, public health research focused on an individual's lifestyle when attempting to explain his/her state of health ${ }^{(1)}$. However, this individualistic approach to explaining the state of a person's health, which is limited to the micro level, has repeatedly demonstrated its limitations ${ }^{(2,3)}$ : although a broad range of biopsychosocial determinants have been taken into consideration in the past, many individual-based risk factor studies have only been partially able to explain health behaviour and health outcomes. It is therefore not surprising that numerous intervention studies which have focused on individuals' behaviour have not resulted in long-term behavioural changes ${ }^{(4)}$.

Pickett and Pearl pointed out in a critical review that this limitation is essentially due to the fact that the individual-based approach does not include factors on an aggregated level, the meso level (especially the geographical context ${ }^{(5)}$ ). Taking the meso level into account by considering the influences of the complex social and physical contexts in which individual behavioural decisions are made has proved to be one way of escaping from this cul-de-sac in contemporary research ${ }^{(6)}$. Recently an increasing number of interdisciplinary research groups have been focusing on investigating to what extent an individual's immediate residential surroundings - his/her social and physical neighbourhood contexts - play a role in determining health behaviour and outcomes ${ }^{(7)}$. In order to do this, direct and indirect influences of neighbourhood contexts on the behaviour and the health of those individuals living there are identified ${ }^{(3,8)}$. Examples of such direct effects include immediate exposure to noise and toxic substances. The 'opportunity structure ${ }^{\text {(9) }}$ of a residential area - meaning, for example, the availability of medical and other facilities (e.g. doctors, ambulant or clinical care facilities) and the built environment (e.g. play grounds and sports fields) - is an example of a factor which has an indirect effect on the behaviour and health of inhabitants ${ }^{(2)}$. A central finding of the research is also that the neighbourhood context accounts for about $10 \%$ of the variation in health outcomes 
and contributes to the emergence and stabilization of health inequalities ${ }^{(10)}$.

Tobacco consumption, alcohol consumption and an unhealthy diet rank among the major health risk factors in developed countries ${ }^{(11)}$. The local availability of tobacco, alcohol and food is especially relevant and worth assessing in the investigation of place effects on health ${ }^{(12)}$. In fact, some studies have previously shown a positive correlation between neighbourhood deprivation and the availability of tobacco ${ }^{(13-18)}$, alcohol $^{(4,19,20)}$ as well as convenience and fast foods ${ }^{(18,21-24)}$.

A recent study examined tobacco and alcohol simultaneously and also found a significantly positive correlation with deprivation indicators for both products ${ }^{(25)}$. Pearce et al. found a positive correlation with deprivation indicators in their joint analysis of alcohol and fast-food outlets $^{(26)}$. However, in the process of our research we could not find any other study which included and mapped tobacco, alcohol and fast-food outlets simultaneously.

The current study takes this approach and addresses the following question using the example of a German megacity: are socially deprived residential areas more likely than affluent areas to provide access to addictive substances and food which can be detrimental to inhabitants' health? In the study, we comply with relevant authors' stipulations regarding both content and methods. These not only call for the consideration of characteristics of the physical environment with regard to such issues, but also for the methodological use of an advanced geographic information system (GIS) ${ }^{(8,9)}$.

\section{Experimental methods}

In the present ecological study ${ }^{(27)}$, the total number of all tobacco, alcohol and fast-food outlets within a predefined investigation area was recorded and visualized using a GIS.

\section{Definition of outcomes and data collection}

As the locations of the outlets of interest are not officially registered, all streets and squares within the defined study area were covered during usual opening hours on foot or by bicycle. The inspection was carried out between October and December 2009 by a geographer (J.G.). All retail locations (e.g. supermarkets, shops, kiosks and gas stations) and catering venues (restaurants, bars and other venues) were checked for tobacco, alcohol and fast-food products. We identified classic providers such as service stations, drugstore chains, owner-managed shops and kiosks, as well as exterior (e.g. wall-mounted) cigarette vending machines and those located inside service establishments (e.g. bars, pubs or restaurants) as tobacco outlets. Every shop, kiosk or restaurant with a product range which included alcohol was defined as an alcohol outlet. Only outlets offering warm takeaway food were classified as fast-food outlets (e.g. hamburger, doner kebab, gyros pita, takeaway pizza, French fries, hot dogs). Outlets which also offered seating without service in addition to takeaway items were also classified as fastfood outlets. Full-service restaurants and venues without a takeaway counter - meaning those that predominantly offered table service - were not included.

\section{Method of geocoding}

Digitalization and geocoding were carried out using the GIS software ESRI ${ }^{\circledR} \operatorname{ArcMap}^{\mathrm{TM}}$ (ArcGIS $^{\mathrm{TM}}$ 9.3; ESRI, Redlands, CA, USA). As a basis for transferring the mapped evaluation data to GIS, we used digital details taken from the 'German National Map' ('Deutsche Grundkarte' DGK5, scale 1:5000) as raster data.

\section{Definition of the investigation area}

Data were collected in Cologne. Located in the Western part of Germany, Cologne is Germany's fourth largest city, with a population of 1020000 inhabitants $^{(28)}$. Cologne is considered to be a 'typical German city' with a historical city centre surrounded by suburbs alongside radial and ring roads. Cologne was chosen for the present study because it is one of the few German cities in which so-called 'social areas' have already been delineated by the Statistical Department of Cologne. 'Social area' is an established (although still heterogeneously used) geographical term defined generally as conjoined clusters of homogeneous streets and houses within a city which share certain characteristics and attributes ${ }^{(29)}$. The complex factor analysis procedure used to define these social areas has been described in detail elsewhere ${ }^{(30)}$. The city of Cologne contains a total of 269 of these social areas.

A visual inspection of the entire city of Cologne would have taken over a year. For our study, eighteen social areas in four districts of Cologne (from west to east: two out of two social areas of Cologne-Junkersdorf, six out of six social areas of Cologne-Lindenthal, eight out of eight social areas of Cologne-Muelheim and two out of two social areas of Cologne-Neubrueck) were chosen. We selected these four districts after having taken into consideration their comparable distance from the city centre as well as their geographical structure: two of these districts are located $7 \mathrm{~km}$ away from the city centre (Cologne-Junkersdorf, Cologne-Neubrueck), while the other two districts are in close proximity to the historical city centre ( $2 \mathrm{~km}$; Cologne-Lindenthal, Cologne-Muelheim). Furthermore, two of these districts (Cologne-Junkersdorf, Cologne-Lindenthal) are located to the west and two (Cologne-Muelheim and Cologne-Neubrueck) to the east of the Rhine River, which runs through the city. Additionally, a representative reflection of Cologne's segregation structures was sought. In short, Cologne-Junkersdorf and CologneNeubrueck are typical suburban areas with mixed geographical development and heterogeneous population structures. Around 10000 inhabitants live in these two districts. In contrast, the districts of Cologne-Lindenthal and 
Cologne-Muelheim both exhibit an urban structure typical of city centre outskirts and are home to 30000 and 40000 inhabitants, respectively.

\section{Definition of status indicators}

Income is considered to be a suitable and widely used indicator of objective deprivation ${ }^{(31)}$. As is usually the case in Germany, no epidemiological data regarding the income of the 91634 inhabitants of the social areas were available due to privacy protection laws. However, for each social area we were able to obtain information regarding the percentage of parents who were exempt from paying kindergarten or full-time school fees for their children. The threshold for exemption from paying such fees is set at a joint annual taxable income of $€ 12272$. At the time of submission of the present paper, this corresponded to \$US 16013. The Department for Children, Youth and Family/Youth Assistance Planning responsible for the City of Cologne emphasizes that it is possible to reach representative conclusions regarding the income situation in social areas by assessing data concerning parents paying [such] fees ${ }^{\text {(32) }}$. Because the income of parents within one district in Germany is therefore likely to correlate strongly with the income of the other inhabitants, we used that income indicator for the entire district. Two measures of income were calculated for each district: (i) the percentage of parents with a joint annual taxable income of $<€ 12272$, which was used for a correlation analysis; and (ii) whether the district percentage of low-income parents was greater or less than $32 \%$ (the mean for the 269 social areas of Cologne), which was used in a comparison of low- and high-income areas. To back up the findings, we took three additional indicators of objective social deprivation into consideration. We had access to data from 2007 regarding youth unemployment rates, the proportion of the population receiving social welfare and the percentage of pupils attending low-qualifying schools in each social area.

\section{Statistical methods}

In the first part of the analysis we examined how accessible the outlets were to the residents. First, all residential buildings within the eighteen social areas were localized ( $\left.n_{\text {buildings }} 11339\right)$. For this purpose the Base DLM (Digital Landscape Model 1:25000, created by the German Federal Agency for Cartography and Geodesy) was used. In the next step the resident population was evenly distributed among the buildings identified within each social area. A separate calculation was necessary because the building structure within the social areas was homogeneous, but varied among the different social areas. As a result, the Euclidean distances from each residential building to the nearest outlet were calculated. To proceed in the most realistic manner, outlets from the neighbouring social areas were also taken into consideration. The accessibility of the outlets investigated consequently equates to the average and weighted Euclidean distance between residential building and outlet.

In the second part of the analysis we examined associations and correlations between deprivation indicators and the number of outlets in social areas. In order to present the outlet density in comparable units for all social areas, the number of identified points of sale was also set in relation to the corresponding number of inhabitants in accordance with usual standards ${ }^{(19)}$. Within bivariate analyses ( $t$ tests for association analyses and Kendall's tau $\beta\left(\tau_{\beta}\right)$ for correlation analyses), the data were normally distributed according to the KolmogorovSmirnov test. Due to very few outlets in the districts of Neubrueck and Muehlheim, we used Kendall's $\tau_{\beta}$ correlation analysis to examine the relationship between deprivation indicators and the number of outlets in social areas. Kendall's $\tau_{\beta}$ correlation coefficients are based on ranks of observations and therefore less vulnerable to outliers than other correlation coefficients ${ }^{(33)}$.

Next, we used Moran's I statistic to test for spatial autocorrelation between the number of tobacco, alcohol and fast-food outlets (which occurs when nearby spatial units are related to each other ${ }^{(34)}$ ). A recent study showed systematic patterns in the spatial distribution of tobacco outlets in 1938 census tracts in the state of New Jersey (USA) that violated the assumption of independence of each observation and caused overestimated coefficients and standard errors ${ }^{(17)}$. Our study was limited to eighteen social areas within four districts of Cologne, and Moran's I statistic indicated no significant spatial autocorrelation. Furthermore, we employed multilevel modelling to test whether the $P$ values and the correlation coefficients might be inflated by the hierarchical data structure. We did not find any variance on the district level and assume that our results are not biased by the clustering of the social areas within districts.

In all cases, we used two-sided tests with $P<0.05$ to indicate statistical significance. All analyses were done using the statistical software package SPSS-PASW Statistics for Windows, version $18 \cdot 0$ (SPSS Inc.), except for the calculation of Moran's I test statistic, which was conducted using GeoDa095-i ${ }^{(35)}$.

\section{Results}

In the entire investigation area, 339 tobacco, 353 alcohol and sixty-seven fast-food outlets were identified, which represents approximately one point of sale per 270, 260 and 1368 inhabitants, respectively. Most tobacco points of sale were cigarette vending machines: forty-eight of them were outdoor and 138 of them were indoor vending machines. Additional tobacco sources included kiosks ( $n$ 85), supermarkets ( $n$ 25), petrol stations ( $n$ 13), drugstores ( $n 10)$, tobacco shops ( $n 8)$ and grocery stores $(n 12)$. The spatial distribution of the commercial tobacco sources 
is shown in the GIS-based map (Fig. 1). It illustrates the almost ubiquitous availability of cigarettes in all areas, with the highest densities along arterial roads and district centres. Any arbitrarily chosen residential building inside the investigation area was situated within a few hundred metres of a commercial tobacco source, at most (range: 0-568 m, mean: $135 \mathrm{~m}$, median: $111 \mathrm{~m}, n_{\text {buildings }} 11339$ ).

The density of outlets offering alcoholic beverages was found to be even higher (Fig. 2). More than half of the alcohol outlets identified were located inside catering venues, namely in restaurants, bars and pubs ( $n$ 194). Kiosks ( $n$ 83) and petrol stations ( $n$ 13) represented approximately a quarter of all alcohol outlets ( $n$ 353) identified. Approximately every ninth outlet identified ( $n$ 41) was a large grocery store/supermarket $(n$ 30) or drugstore ( $n$ 11) and about $7 \%$ were specialty stores such as wine and spirit shops, delicatessens, etc.

The Euclidean distances between the residential buildings and the nearest outlet amounted on average to between 82 and $151 \mathrm{~m}$ for tobacco (Fig. 1) and 92 and $175 \mathrm{~m}$ for alcohol, depending on the district (Fig. 2). In comparison, fast-food points of sale were found to be further away from residential buildings (194-782 m, Fig. 3). Twenty-two out of a total of sixty-seven points of sale were solely takeaway outlets. The remaining outlets also offered the possibility to eat while standing or sitting (e.g. food chains/catering industry).

Next we examined the association between neighbourhood deprivation and local supply. We compared all social areas of above-average income with all those of

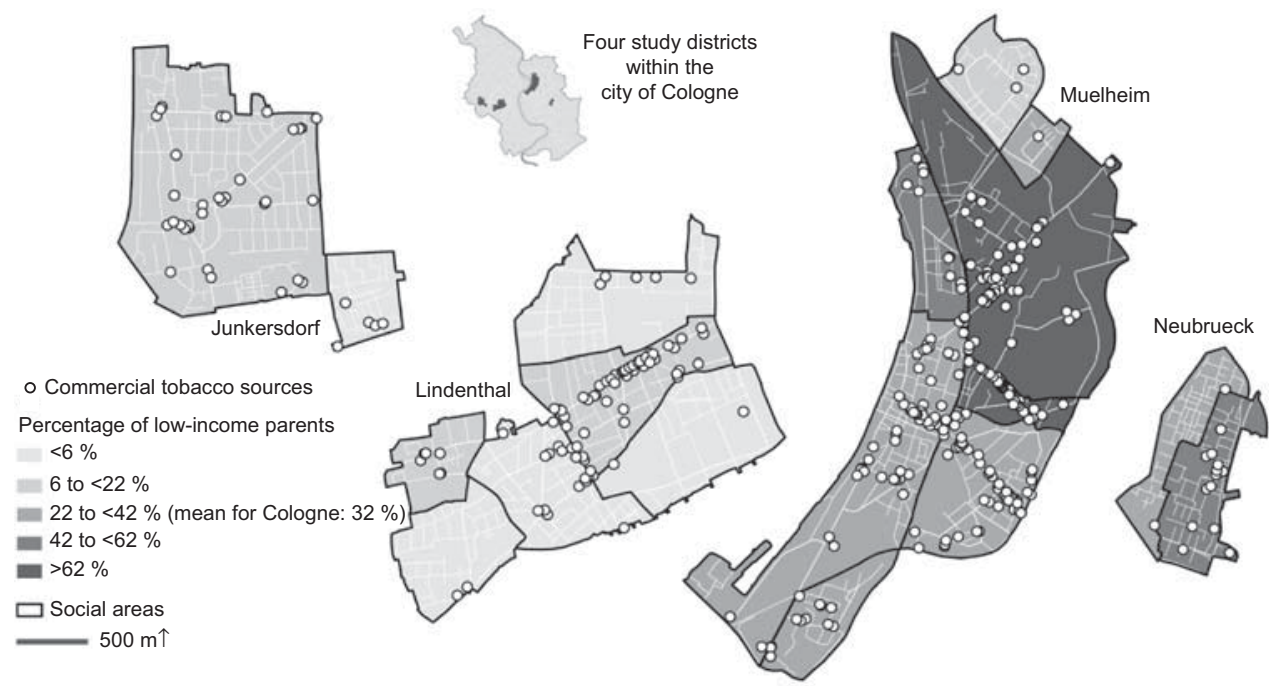

Fig. 1 True to scale, cartographic depiction of all tobacco outlets in eighteen social areas of the city of Cologne, Germany, autumn 2009

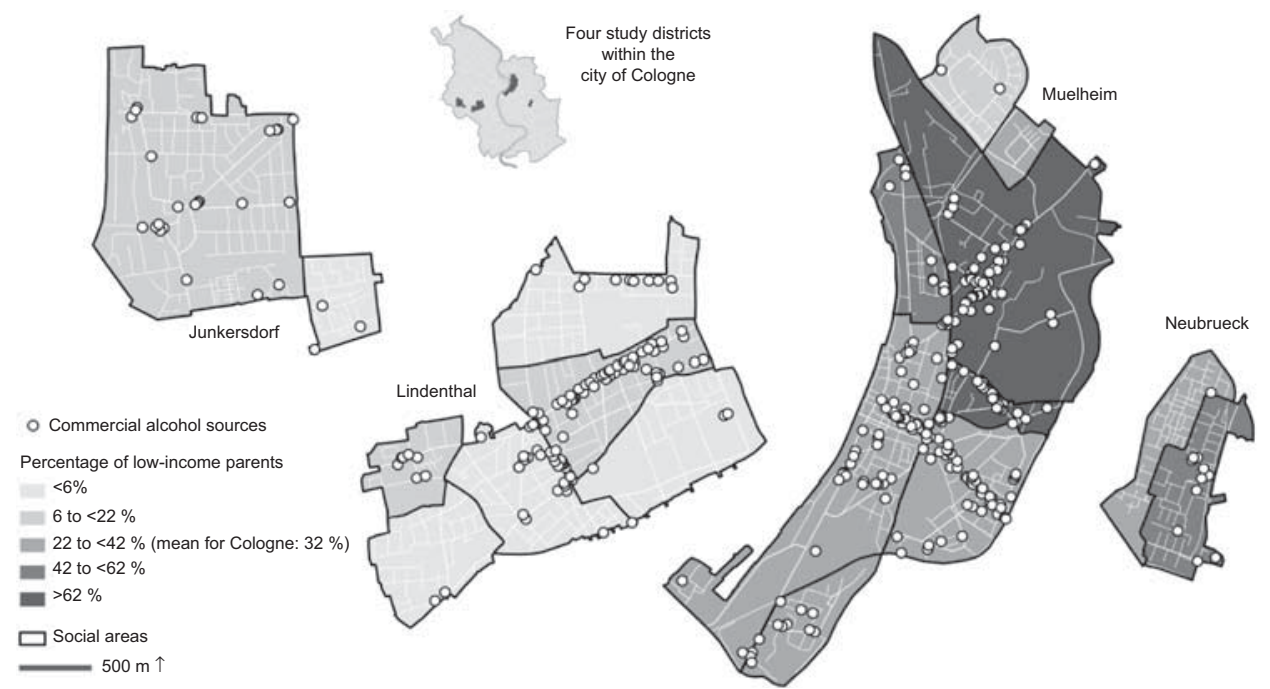

Fig. 2 True to scale, cartographic depiction of all alcohol outlets in eighteen social areas of the city of Cologne, Germany, autumn 2009 


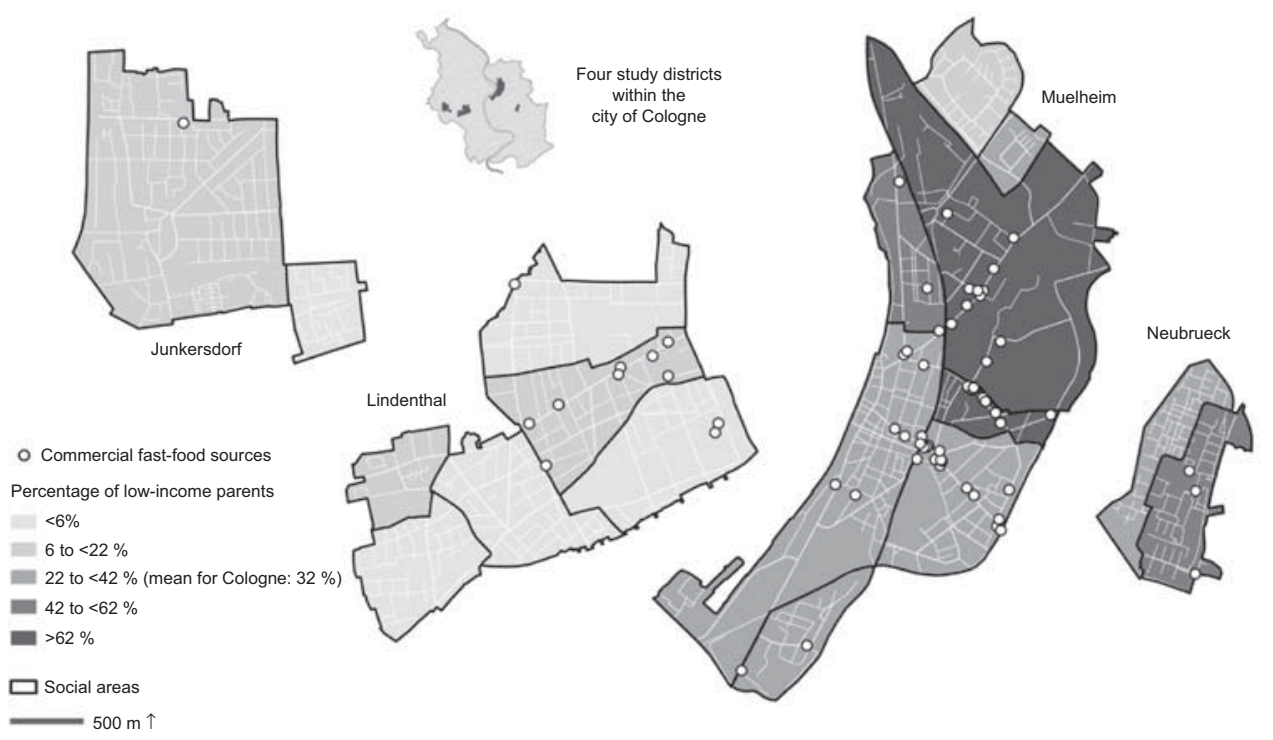

Fig. 3 True to scale, cartographic depiction of all fast-food outlets in eighteen social areas of the city of Cologne, Germany, autumn 2009

below-average income with respect to the density of points of sale. With $4 \cdot 70$ tobacco sources per 1000 inhabitants, we found significantly more commercial cigarette sources in the disadvantaged districts than in the affluent districts, where the density was $2 \cdot 67$ per 1000 inhabitants $(t=-2 \cdot 22 ; \quad P=0 \cdot 041)$. Differences were also seen regarding alcohol and fast food: the number of outlets in the disadvantaged districts was $4 \cdot 70$ and $1 \cdot 19$ per 1000 inhabitants, respectively. In the more affluent districts, the number of commercial sources per 1000 inhabitants was 2.98 for alcohol $(t=-1.58 ; P=0 \cdot 134)$ and $0 \cdot 27$ for fast food $(t=-2 \cdot 44 ; P=0 \cdot 042)$.

Neighbourhood deprivation showed a clear association with the average distance to the nearest outlet: whereas the residential population in the ten more affluent areas had an average Euclidean distance of $151 \mathrm{~m}$ (tobacco), $166 \mathrm{~m}$ (alcohol), $511 \mathrm{~m}$ (fast food) to the next point of sale, these distances amounted to $85 \mathrm{~m}$ (tobacco), $99 \mathrm{~m}$ (alcohol), $177 \mathrm{~m}$ (fast food) in the eight disadvantaged districts. Legal drugs and fast food were significantly $(P<0 \cdot 05)$ more accessible to the residents of socially disadvantaged districts.

In more detailed analyses, significant correlations between the income indicator and outlet density were also found for all three categories of product which can be detrimental to inhabitants' health: the lower the income in a district, the higher the availability of cigarettes, alcohol and fast food (Figs 4-6). This correlation was strongest for fast food $\left(\tau_{\beta}=0.473 ; P=0.009\right)$, followed by tobacco products $\left(\tau_{\beta}=0.433 ; P=0 \cdot 012\right)$ and alcohol $\left(\tau_{\beta}=0 \cdot 341, P=0 \cdot 049\right)$.

Correlation coefficients for the three alternative indicators of youth unemployment $\left(\tau_{\beta}(\right.$ tobacco $)=0 \cdot 322$; $\tau_{\beta}($ alcohol $)=0 \cdot 257 ; \tau_{\beta}($ fast food $\left.)=0 \cdot 496\right)$, the percentage of people receiving social welfare $\left(\tau_{\beta}(\right.$ tobacco $)=0 \cdot 289$; $\tau_{\beta}($ alcohol $)=0 \cdot 184 ; \tau_{\beta}($ fast food $\left.)=0 \cdot 409\right)$ and the percentage of pupils attending low-qualifying schools $\left(\tau_{\beta}(\right.$ tobacco $)=0 \cdot 268 ; \tau_{\beta}($ alcohol $)=0 \cdot 229 ; \tau_{\beta}($ fast food $)=$ $0 \cdot 450)$ indicated a similar tendency, but were significant only in the case of fast food $(0 \cdot 006<P<0 \cdot 023)$.

\section{Discussion}

\section{Principal findings and contribution to the current state of research}

In residential areas with low income and high deprivation levels, the availability of unhealthy products was significantly higher than in more affluent areas. The density of outlets which provide alcohol and tobacco, as well as those offering unhealthy food, correlated significantly with the social structure of a specific residential area. Thus, the physical environment, specifically discrepancies in the availability of fast food and addictive substances, can have a contextual influence on the health of an individual and can, in the form of physical exposure, contribute to a further culmination of health risks.

Based on the term 'obesogenic environments',(26,36), we suggest that there are also 'addictive environments' which cluster in socially disadvantaged neighbourhoods. This is consistent with relevant literature which we summarized in the paper's introduction. (By contrast, the literature on the relationship between neighbourhood deprivation and the accessibility of healthy food (like fruit and vegetables) is inconsistent ${ }^{(4,23,26,37)}$.) That such a higher exposure is in fact correlated with a higher demand is confirmed by several studies on tobacco and alcohol ${ }^{(18,38,39)}$. Several authors report spatial aggregation structures in the form 


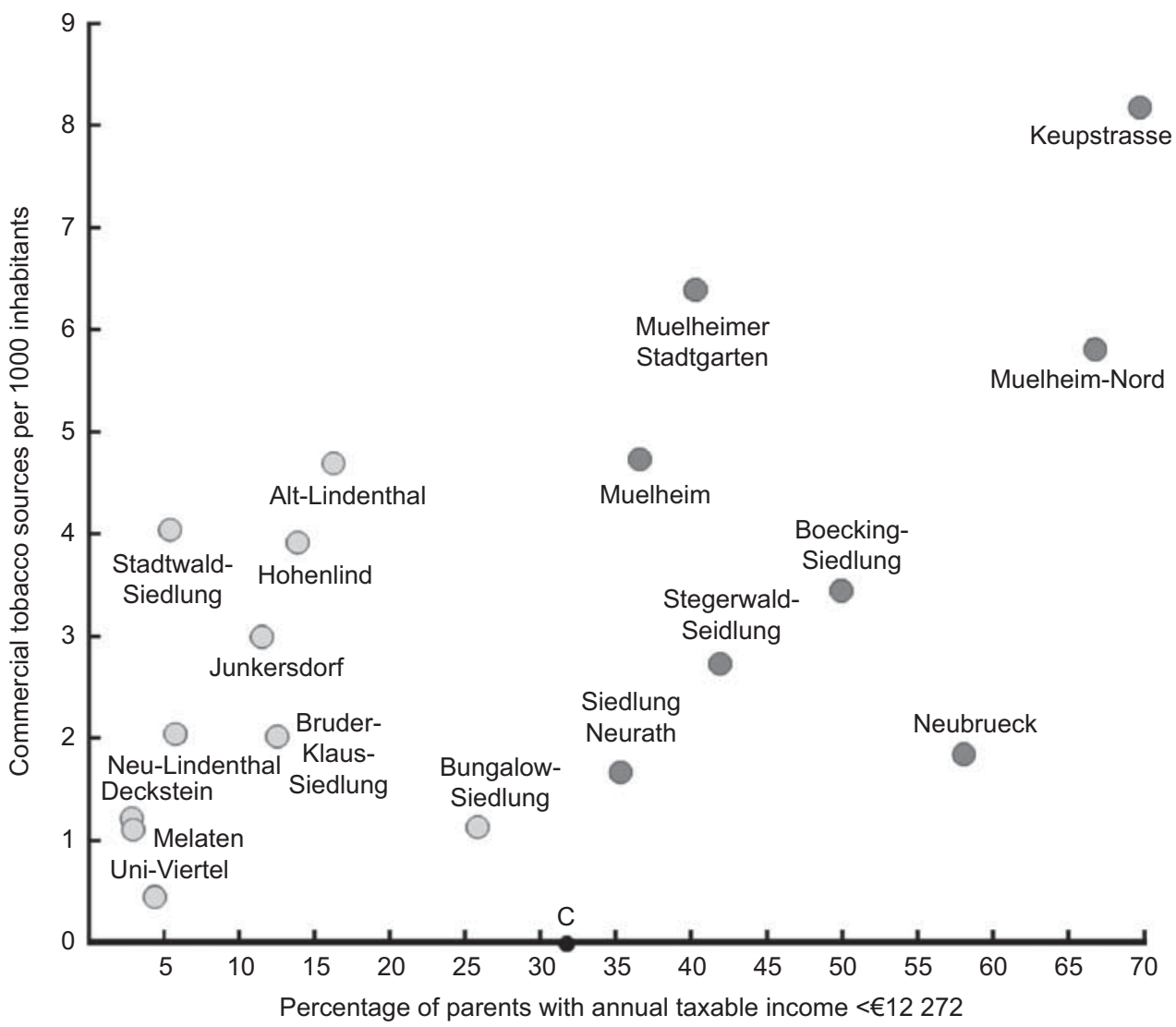

Fig. 4 Scatter plot for the correlation between an income indicator and tobacco outlet density in eighteen social areas of the city of Cologne, Germany, autumn 2009. $\tau_{\beta}=0.433, P=0.012 ; C=$ mean for city of Cologne; $\mathrm{C}$, social areas with under-average income indicator; , social areas with above-average income indicator; income indicator = parents with a joint annual taxable income $<€ 12272$ within the social area/all parents within the social area (in \%)

of so-called 'smoking islands' ${ }^{\text {(40) }}$. According to three current reviews, the majority ${ }^{(23,41,42)}$ but not all $^{(43,44)}$ of the studies also identified a significant association between a healthy community food environment and limited access to fastfood restaurants, on the one hand, and healthy diets and lower obesity rates on the other hand.

Consequently, our results support the thesis of 'depri-

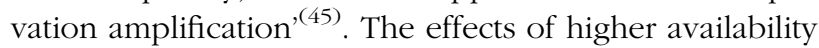
of fast-food and legal drug outlets is further amplified because disadvantaged groups are less likely to own a car and are therefore less mobile, making them less able to obtain alternative, healthy products (e.g. organic food, fresh fruits and vegetables) ${ }^{(4)}$. It is possible that these phenomena on the meso level could help to partially explain the widening gap in social and health inequalities $^{(22,26,46)}$. In our conclusion we take up suggestions recently made by the WHO and other research groups as to how such a deprivation amplification could be countered on the meso level ${ }^{(18,25,47-49)}$.

\section{Limitations and strengths}

Methodical limitations of the present study mainly concern the selection of the study area, the clustering of social areas and the inability to assess causality. Strengths of the study include the simultaneous consideration of the availability of tobacco, alcohol and fast-food products, the use of innovative GIS methods to visualize the number and distribution of outlets, and the comprehensive and valid data collection process which included every outlet in an extensive geographic investigation area.

\section{Selectivity of the area of investigation}

Although we have termed Cologne a 'typical German city', it cannot be considered to be representative of all German cities. Nevertheless, the proportion of persons aged $0-25$ years amounted to $24 \cdot 3 \%$ (compared with the Germany-wide average of $25 \cdot 8 \%$ ) and the unemployment rate was $13 \cdot 1 \%$ (compared with the Germany-wide average of $11.7 \%$ ), and therefore the city can be said to be typical of the nationwide urban situation.

\section{Clustering of social areas}

We used a stratified sample design to identify eighteen social areas clustered within four different districts. In this way we were able to economize field time and field costs. We intentionally incorporated districts with different social and geographical structures into the study, which provided a key basis for comparison. However, this design can 


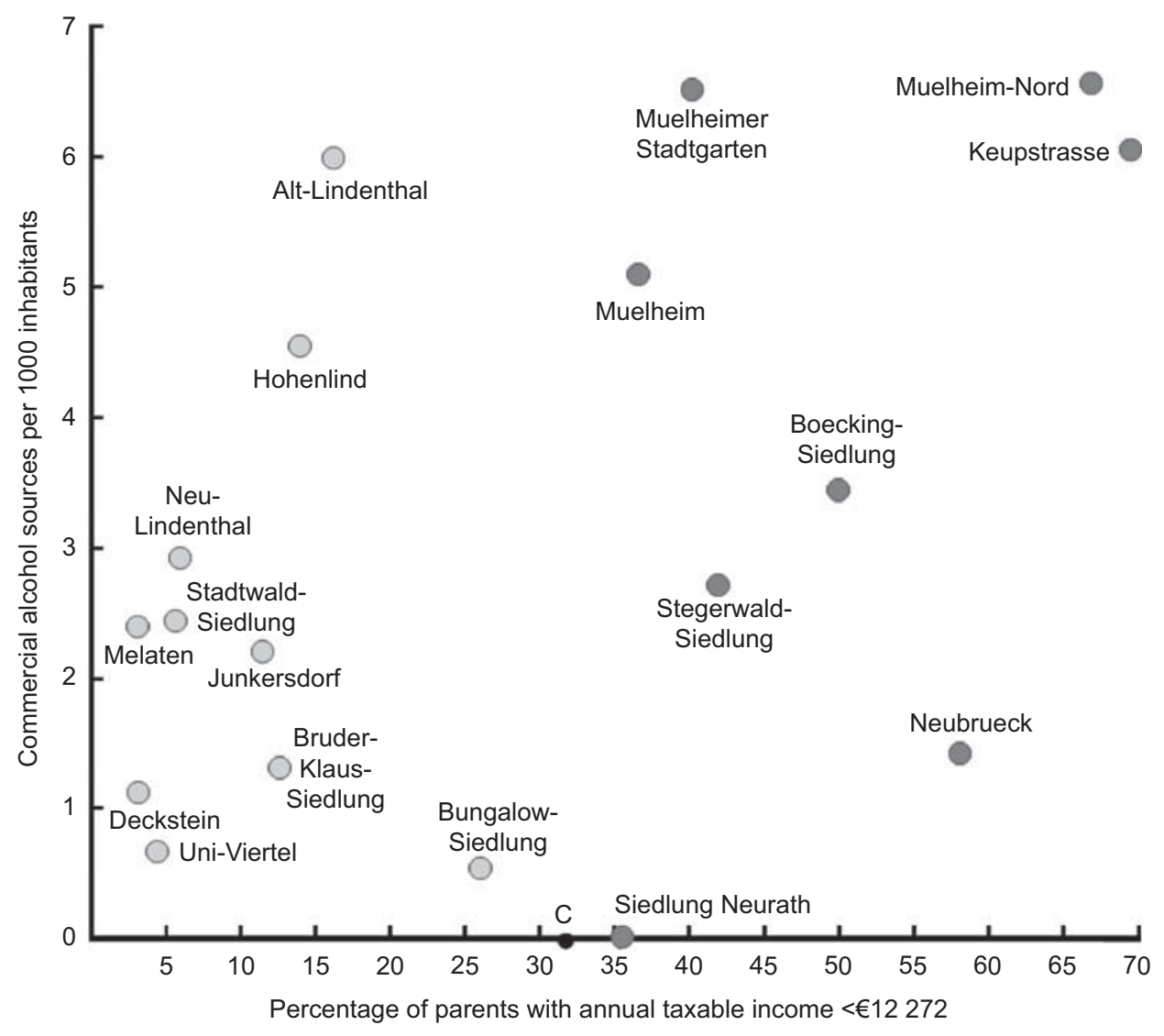

Fig. 5 Scatter plot for the correlation between an income indicator and alcohol outlet density in eighteen social areas of the city of Cologne, Germany, autumn 2009. $\tau_{\beta}=0.341, P=0.049 ; \mathrm{C}=$ mean for city of Cologne; $\mathrm{O}$, social areas with under-average income indicator; social areas with above-average income indicator; income indicator = parents with a joint annual taxable income $<€ 12272$ within the social area/all parents within the social area (in \%)

produce spatial autocorrelation because social areas within the same district are likely to have similar numbers of outlets and a similar social structure ${ }^{(4,13)}$. If spatial autocorrelation occurs and spatial units in close proximity are related to each other, the assumption of independence in classical statistical models is violated and the type I error is inflated ${ }^{(50)}$. We therefore carefully checked the dependent variables by social area for spatial autocorrelation using Moran's $I$ test statistic and did not observe any significant spatial clustering. Furthermore, we used multilevel modelling to test whether the reported coefficients and $P$ values were biased by the hierarchical data structure and socio-economic differences between the four districts. We did not find any variance on the district level (results not shown) and therefore applied classic statistical non-parametric models.

\section{Inability to assess causality}

An ecological study such as this one can naturally not come to conclusions regarding the causal direction of the correlations observed $^{(48)}$. First, it is possible that investors follow demand and open and run their stores in areas where they expect the highest buyer density ('supply follows demand $\left.{ }^{(4)}\right)$. Correspondingly, over-proportionally high tobacco advertisement density has been observed in socially deprived areas ${ }^{(14,51,52)}$. Second, it is possible that tenants and home owners move to areas where they have access to their preferred products (according to their preference, either healthy or unhealthy products;

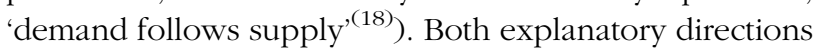
are concordant with economic theory, which posits that the net price faced by consumers is a function of search costs. Search costs include time necessary and distance travelled by individuals to the point of sale. Thus, the higher the outlet density, the lower the subjective costs $^{(53)}$. As individuals with a lower social status are particularly price sensitive, lowering access costs (e.g. reduced travelling time) is likely to increase their consumption ${ }^{(53)}$. Suppliers (the tobacco, alcohol and fastfood industries, as well as vending machine distributors) are just as likely to take these points into consideration when planning the location of their outlets as consumers are when deciding where they want to live. However, the cause of this pivotal correlation is not as important for the public health message of our study as the resulting consequences regarding neighbourhood environment and health. In addition to the supply of unhealthy foods, future studies on neighbourhood context and health 


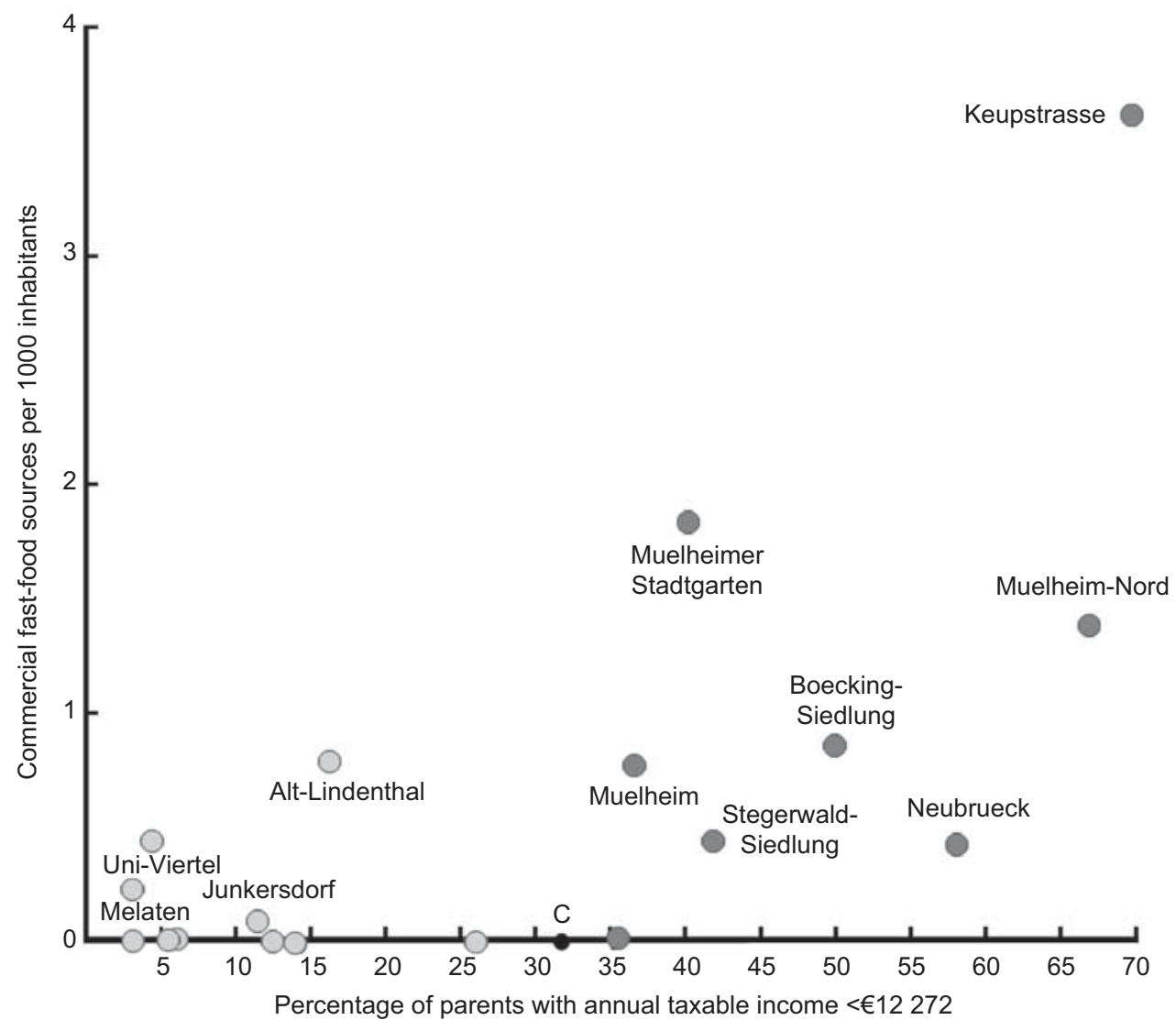

Fig. 6 Scatter plot for the correlation between an income indicator and fast-food outlet density in eighteen social areas of the city of Cologne, Germany, autumn 2009. $\tau_{\beta}=0.473, P=0.009 ; \mathrm{C}=$ mean for city of Cologne; $\mathrm{C}$, social areas with under-average income indicator; , social areas with above-average income indicator; income indicator = parents with a joint annual taxable income $<€ 12272$ within the social area/all parents within the social area (in \%)

should simultaneously take the supply of healthy foods (e.g. fresh fruit and vegetables) into account.

To our knowledge the present study is the first to map tobacco, alcohol and fast-food outlets simultaneously using a GIS, which provides information not only about the number, but also about the spatial distribution and density of sources. The comparatively extensive area of investigation and the topicality, thoroughness and validity of the data collection are further strengths of this study. In this way we have fulfilled the stipulations of several authors who had previously questioned the validity of the data (such as selected outlets, register data or participant reports $\left.{ }^{(18,21,53-55)}\right)$ and criticized the lack of cartographic GIS mapping in similar studies ${ }^{(19)}$.

\section{Conclusions}

Our study demonstrates the link between social and physical contextual factors on the meso level. It can be said that those individuals who are already socially disadvantaged experience a further contextual disadvantage due to their place of residence.
Possible intervention measures to prevent deprivation amplification on the meso level can be initiated on the supply side or on the demand side. On the supply side, the WHO and the aforementioned research groups recommend - among other things - legal age barriers, licensing laws and restrictions on advertising and on local outlet density. In our opinion this should also include the strict prohibition of publicly accessible cigarette vending machines. In Germany, Austria, Italy and Japan such machines are freely accessible on the walls of buildings and in front of tobacconists. In Germany the high-risk group, which includes children and adolescents, is supposed to be protected via non-regulative (and barely effective) commitments made by the cigarette industry and vending machine operators according to which they are not allowed to install poster advertising (within $100 \mathrm{~m}$ ) or cigarette vending machines (within $50 \mathrm{~m}$ ) within a certain distance of schools or youth facilities. Local disparities in the supply of alternative foods could be balanced, at least to a small degree, by enabling higher permeability between neighbourhoods. This could be done, for example, by improving the public transportation system or the network of cycling paths and sidewalks. An adequate settlement 
policy (retail mix, health-promoting urban planning of new residential areas and industrial settlements) could counteract negative social differentiation due, for example, to the non-regulated gentrification, segregation or deprivation of whole neighbourhoods. In Germany, for example, each municipal district is responsible for its own retail planning. This type of retail planning employs very detailed product lists to ensure that all residents (also those who are not mobile) have access to a wide range of products. It would therefore be very possible to take health-related issues into consideration in such retail planning processes, allowing targeted intervention on the supply side.

On the demand side, besides better communication about health risks and public health empowerment, promoting diverse shopping facilities (e.g. organic markets) and therapy options in socially disadvantaged areas (e.g. local advertising), the prevention of the onset and the promotion of cessation of tobacco, alcohol or fast-food consumption are central intervention strategies on the meso level. Lifestyle-specific prevention campaigns in schools, youth and old-age facilities, poster campaigns as well as outreach work should be offered, especially in socially disadvantaged districts. Additionally, incentive and support systems (bonification, deductions, quit lines and help lines) could motivate decision makers and disseminators (physicians, pharmacies and teachers) in critical social neighbourhoods to offer tobacco and alcohol cessation courses and to provide nutrition counselling. Furthermore, all of these measures should consider the specific social structure (including migrants) of the respective districts through multilingual and a low-threshold implementation.

\section{Acknowledgements}

Source of funding: This research received no specific grant from any funding agency in the public, commercial or not-for-profit sectors. According to German law an ethical approval was not required as no personal data were used. Conflicts of interest: The authors had no conflict of interest. Authors' contribution: S.S. was the principal investigator. J.G. conducted the field work of the study, including geocoding. Both authors prepared data management, statistical analyses and figures and wrote the manuscript. Acknowledgements: Without the wealth of statistical information provided by the personnel of the Office for Youth Support in the Department of Youth, Children and Family Welfare, namely Mr Heymann, Mrs Langenbach and $\mathrm{Mr}$ Gringmuth-Held, this study would not have been possible. Moreover, the authors would like to thank Professor Thomas Kistemann (Institute for Hygiene and Public Health, University of Bonn) for methodological ideas; Shelby Yamamoto, PhD, and Silke Roehrig, BA, for their helpful comments and support in the preparation of the manuscript; as well as Christian Weidmann, MA, for his statistical programming support.

\section{References}

1. Diez Roux AV (2001) Investigating neighborhood and area effects on health. Am J Public Health 91, 1783-1789.

2. Mohnen SM (2012) Neighborhood Context and Health: How Neighborhood Social Capital Affects Individual Health Utrecht: ICS.

3. Diez Roux AV \& Mair C (2010) Neighbourhoods and health. Ann N Y Acad Sci 1186, 125-145.

4. Morland K, Wing S, Diez Roux A et al. (2002) Neighborhood characteristics associated with the location of food stores and food service places. Am J Prev Med 22, 23-29.

5. Pickett KE \& Pearl M (2001) Multilevel analyses of neighbourhood socioeconomic context and health outcomes: a critical review. J Epidemiol Community Health 55, $111-122$

6. Cummins S \& Macintyre S (2006) Food environments and obesity - neighbourhood or nation? Int J Epidemiol 35, 100-104

7. Patterson JM, Eberly LE, Ding Y et al. (2004) Associations of smoking prevalence with individual and area level social cohesion. J Epidemiol Community Health 58, 692-697.

8. van Lenthe FJ (2006) Aggregate deprivation and effects on health. In: Social Inequalities in Health: New Evidence and Policy Implications, pp. 167-192 [J Siegrist and M Marmot, editors]. Oxford: Oxford University Press.

9. Macintyre S, Ellaway A \& Cummins S (2002) Place effects on health: how can we conceptualise, operationalise and measure them? Soc Sci Med 55, 125-139.

10. Sellström E \& Bremberg S (2006) The significance of neighbourhood context to child and adolescent health and well-being: a systematic review of multilevel studies. Scand $J$ Public Health 34, 544-554.

11. Ezzati M, Hoorn SV, Rodgers A et al. (2003) Estimates of global and regional potential health gains from reducing multiple major risk factors. Lancet 362, 271-280.

12. van Lenthe FJ \& Mackenbach JP (2002) Neighbourhood deprivation and overweight: the GLOBE study. Int J Obes Relat Metab Disord 26, 234-240.

13. Hyland A, Travers MJ, Cummings KM et al. (2003) Tobacco outlet density and demographics in Erie County, New York. Am J Public Health 93, 1075-1076.

14. Laws MB, Whitman J, Bowser DM et al. (2002) Tobacco availability and point of sale marketing in demographically contrasting districts of Massachusetts. Tob Control 11, ii71-ii73.

15. Siahpush M, Jones PR, Singh GK et al. (2010) Association of availability of tobacco products with socio-economic and racial/ethnic characteristics of neighbourhoods. Public Health 124, 525-529.

16. Siahpush M, Jones PR, Singh GK et al. (2010) The association of tobacco marketing with median income and racial/ethnic characteristics of neighbourhoods in Omaha, Nebraska. Tob Control 19, 256-258.

17. Yu D, Peterson NA, Sheffer MA et al. (2010) Tobacco outlet density and demographics: analysing the relationships with a spatial regression approach. Public Health 124, 412-416.

18. Chuang YC, Cubbin C, Ahn D et al. (2005) Effects of neighbourhood socioeconomic status and convenience store concentration on individual level smoking. J Epidemiol Community Health 59, 568-573.

19. Duncan SC, Duncan TE \& Strycker LA (2002) A multilevel analysis of neighborhood context and youth alcohol and drug problems. Prev Sci 3, 125-133.

20. Berke EM, Tanski SE, Demidenko E et al. (2010) Alcohol retail density and demographic predictors of health disparities: a geographic analysis. Am J Public Health 100, 1967-1971.

21. Moore LV, Diez Roux AV, Nettleton JA et al. (2009) Fast-food consumption, diet quality, and neighborhood exposure to 
fast food: the multi-ethnic study of atherosclerosis. Am J Epidemiol 170, 29-36.

22. Moore LV \& Diez Roux AV (2006) Associations of neighborhood characteristics with the location and type of food stores. Am J Public Health 96, 325-331.

23. Larson NI, Story MT \& Nelson MC (2009) Neighborhood environments: disparities in access to healthy foods in the US. Am J Prev Med 36, 74-81.

24. Pearce J, Blakely T, Witten K et al. (2007) Neighborhood deprivation and access to fast-food retailing: a national study. Am J Prev Med 32, 375-382.

25. Ogneva-Himmelberger Y, Ross L, Burdick W et al. (2010) Using geographic information systems to compare the density of stores selling tobacco and alcohol: youth making an argument for increased regulation of the tobacco permitting process in Worcester, Massachusetts, USA. Tob Control 19, 475-480.

26. Pearce J, Day P \& Witten K (2008) Neighbourhood provision of food and alcohol retailing and social deprivation in urban New Zealand. Urban Policy Res 26, 213-227.

27. Morgenstern H (1995) Ecologic studies in epidemiology: concepts, principles, and methods. Annu Rev Public Health 16, 61-81.

28. Stadt Köln (2010) Statistisches Jahrbuch 2008/2009 (Statistical Year Book 2008/2009). Köln: Amt für Stadtentwicklung und Statistik.

29. Shevky E \& Bell W (1955) Social Area Analysis: Theory, Illustrative Application and Computational Procedure. Stanford, CA: Stanford University Press.

30. Heymann H (2005) Sozialraumanalyse in Köln. In: Sozialraumanalyse: Grundlagen - Methoden - Praxis (Analysis of the Social Region: Basics - Methods - Practice), pp. 241-259 [M Riege and H Schubert, editors]. Wiesbaden: VS Verlag.

31. Townsend P (1987) Deprivation. J Soc Policy 16, 125-146.

32. Stadt Köln (2005) Erläuterung der Sozialraumdaten (Comment on Social Area Information). Köln: Amt für Kinder, Jugend und Familie.

33. Sommer BB \& Sommer R (2002) A Practical Guide to Behavioral Research: Tools and Techniques. New York: Oxford University Press.

34. Anselin L \& Rey S (2010) Perspectives on Spatial Data Analysis. Berlin: Springer.

35. Anselin L, Syabri I \& Kho Y (2006) An introduction to spatial data analysis. Geogr Anal 38, 5-22.

36. Lake A, Townshend T \& Alvanides S (2010) Obesogenic Environments. New York: John Wiley \& Sons.

37. Cummins S, Smith DM, Taylor M et al. (2009) Variations in fresh fruit and vegetable quality by store type, urban-rural setting and neighbourhood deprivation in Scotland. Public Health Nutr 12, 2044-2050.

38. Asumda F \& Jordan L (2009) Minority youth access to tobacco: a neighborhood analysis of underage tobacco sales. Health Place 15, 140-147.

39. Gibbons FX, Gerrard M, Vande Lune LS et al. (2004) Context and cognitions: environmental risk, social influence, and adolescent substance use. Pers Soc Psychol Bull 30, 1048-1061.
40. Thompson L, Pearce J \& Barnett R (2007) Moralising geographies: stigma, smoking islands and responsible subjects. Area 39, 508-517.

41. Jago R, Baranowski T \& Baranowski JC (2007) Fruit and vegetable availability: a micro environmental mediating variable? Public Health Nutr 10, 681-689.

42. Holsten JE (2009) Obesity and the community food environment: a systematic review. Public Health Nutr 12, 397-405.

43. Pearce J, Hiscock R, Blakely T et al. (2008) The contextual effects of neighbourhood access to supermarkets and convenience stores on individual fruit and vegetable consumption. J Epidemiol Community Health 62, 198-201.

44. Pearce J, Hiscock R, Blakely T et al. (2009) A national study of the association between neighbourhood access to fastfood outlets and the diet and weight of local residents. Health Place 15, 193-197.

45. Dunn J, Frohlich K \& Ross N (2006) Role of geography in inequalities in health and human development. In Healthier Societies: From Analysis to Action, pp. 237-266 [J Heymann, C Hertzmann, ML Barer et al., editors]. New York: Oxford University Press.

46. Barnett R, Pearce J \& Moon G (2009) Community inequality and smoking cessation in New Zealand, 1981-2006. Soc Sci Med 68, 876-884.

47. Ashe M, Jernigan D, Kline R et al. (2003) Land use planning and the control of alcohol, tobacco, firearms, and fast food restaurants. Am J Public Health 93, 1404-1408.

48. Schulz A \& Northridge ME (2004) Social determinants of health: implications for environmental health promotion. Health Educ Behav 31, 455-471.

49. World Health Organization (2011) Global Status Report on Noncommunicable Diseases 2010: Description of the Global Burden of NCDs, their Risk Factors and Determinants. Geneva: WHO.

50. Ward M \& Gleditsch K (2008) Spatial Regression Models. Los Angeles, CA: Sage.

51. Feighery EC, Schleicher NC, Boley Cruz T et al. (2008) An examination of trends in amount and type of cigarette advertising and sales promotions in California stores, 2002-2005. Tob Control 17, 93-98.

52. Meyer C \& Schneider S (2007) Tabakbezugsquellen und Tabakwerbung im Umfeld von Kölner Schulen - Beispiel für den Einsatz eines geographischen Informationssystems in der Public-Health-Forschung (Tobacco supply sources and tobacco advertising near schools - example of the use of a geoinformation system in public health research). Präv Gesundheitsf 2, 211-220.

53. Schneider JE, Reid RJ, Peterson NA et al. (2005) Tobacco outlet density and demographics at the tract level of analysis in Iowa: implications for environmentally based prevention initiatives. Prev Sci 6, 319-325.

54. Harrington DW \& Elliott SJ (2009) Weighing the importance of neighbourhood: a multilevel exploration of the determinants of overweight and obesity. Soc Sci Med 68 , 593-600.

55. Pearce J, Hiscock R, Moon G et al. (2009) The neighbourhood effects of geographical access to tobacco retailers on individual smoking behaviour. I Epidemiol Community Health 63, 69-77. 